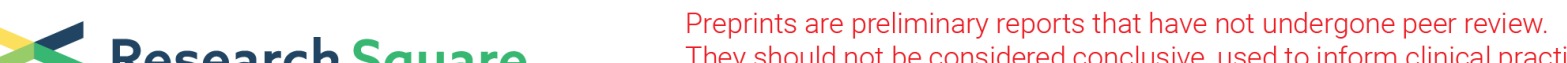 $\begin{array}{ll}\text { Research Square } & \begin{array}{l}\text { They should not be considered conclusive, used to inform clinical practice, } \\ \text { or referenced by the media as validated information. }\end{array}\end{array}$
}

\section{Prevalence and risk factors of silent obstructive sleep apnea in patients with dentofacial deformities}

Rei Jokaji

Kanazawa Daigaku Daigakuin lyaku Hokengaku Sogo Kenkyuka lyaku Hoken Gakuiki Igakurui

Kazuhiro Ooi ( $\sim$ k-ooi@staff.kanazawa-u.ac.jp)

Kanazawa University Graduate School of Medical Science https://orcid.org/0000-0002-1678-0158

\section{Sayuri Takamichi}

Kanazawa University Graduate School of Medicine

\section{Yusuke Nakade}

Kanazawa Daigaku Daigakuin lyaku Hokengaku Sogo Kenkyuka lyaku Hoken Gakuiki Igakurui

\section{Shuichi Kawashiri}

Kanazawa Daigaku Daigakuin lyaku Hokengaku Sogo Kenkyuka lyaku Hoken Gakuiki Igakurui

\section{Kazuo Kasahara}

Kanazawa University Graduate

\section{Masako Nakata}

Kanazawa University Graduate

\section{Research article}

Keywords: silent obstructive sleep apnea, dentofacial deformity, prevalence, risk factor, polysomnography

Posted Date: April 5th, 2021

DOl: https://doi.org/10.21203/rs.3.rs-381093/v1

License: (c) (i) This work is licensed under a Creative Commons Attribution 4.0 International License.

Read Full License 


\section{Abstract \\ Objective}

Prevalence of silent obstructive sleep apnea (OSA) in patients with dentofacial deformities is unknown, although OSA is severe risk of airway obstruction in perioperative orthognathic surgery or complication after surgery. The aim of this study was to investigate prevalence and risk factors of silent OSA in patients with dentofacial deformities.

\section{Methods}

We analyzed 72 patients ( 24 male, 48 female) with dentofacial deformities without previous OSA symptoms. Polysomnography was performed before orthognathic surgery. Prevalence and risk factors of silent OSA were statistically analyzed as related to Apnea hypopnea index (AHI).

\section{Results}

Mean AHI was 1.6 (range: 0-12.1) /h. Three patients of 72 patients (4.1\%) were diagnosed silent OSA. AHI during REM sleep phase 3.7 (0-32.3) was higher than AHI during NREM sleep phase 1.0 (0-9.7). AHI of male patients was higher than that of female. AHI was increased according to high BMI. AHI was higher in deep bite than open bite, edge to edge bite and nomal bite. AHI of mandibular asymmetry cases were higher than that of symmetry cases.

\section{Conclusions}

The prevalence of silent OSA was $4.1 \%$. Obesity, male, deep bite, mandibular asymmetry and REM sleep phase were risk factors of silent OSA.

\section{Introduction}

Dentofacial deformity is a condition involving maxillofacial abnormalities and skeletal malocclusion with a variety of acquired or congenital causes, including abnormal growth and development of the jaw, trauma, and postoperative tumor resection. Regardless of the presence of subjective symptoms, it is likely to cause problems with oral functions such as mastication, swallowing, articulation, and breathing. Sleep plays an important role in the maintenance of physiological and psychological functions. Obstructive sleep apnea (OSA) is the most common type of sleep disorder and is characterised by repeated episodes of complete or partial obstructions of the upper airway during sleep ${ }^{1}$. OSA is thought to be associated with traffic accidents due to excessive daytime sleepiness and the development of cerebral and cardiovascular diseases ${ }^{2}$. The risk of OSA due to anatomical stenosis of the upper respiratory tract is 
high in patients with micromandible ${ }^{3}$. Respiratory is necessary to consider not only the morphology but also the function as well as the mastication and articulation. In the perioperative period of orthognathic surgery, airway management is one of the most important perioperative management, and there is a risk of airway obstruction due to the effects of postoperative swelling, bleeding, trismus, and intermaxillary elastic traction. Emergency tracheal intubation or tracheostomy after orthognathic surgery have been reported ${ }^{4}$. A more recent study reports that unstable sleep, called REM rebound, increases with changes in sleep after general anesthesia, and that airway risk is particularly high in perioperative management for OSA patients ${ }^{5}$. It is well known that OSA may be improved in patients with micromandible by mandibular advancement ${ }^{6,7}$. In recent years, sleep surgery by maxillomandibular advancement (MMA) for OSA has developed ${ }^{8}$. However, the mandibular body must be moved to the posterior position by orthognathic surgery in mandibular prognathism, so it is undeniable that the pharyngeal cavity is constricted and causes OSA. Although the risk of OSA after orthognathic surgery in mandibular prognathism is thought to be low because mandibular prognathism has a wider airway than that of normal occlusion without dentofacial deformities ${ }^{9}$. Incidence of OSA after mandibular setback in mandibular prognathism was reported however the status of OSA in mandibular prognathism and the risk of mandibular setback has not been fully investigated ${ }^{10}$. Therefore, considering the safety of orthognathic surgery, evaluation of OSA status and perioperative airway in patients with dentofacial deformities is extremely important. These days, three-dimensional image examination has progressed and many simulations of occlusal and facial morphology have been reported in orthognathic surgery, but airway changes in orthognathic surgery have been evaluated using standard X-ray photographs of the head ${ }^{11}$. However, it is not always said that functional airway evaluation is performed because it is evaluated based on the images at the temporary points taken. However, OSA in patients with dentofacial deformities have been evaluated before and after surgery using images such as CT images and cephalometric X-ray photographs postoperatively ${ }^{12}$. Although a functional evaluation has been reported after a long period of time $\mathrm{e}^{13}$, OSA evaluation using polysomnography and perioperative functional evaluation in mandibular prognathism have hardly been performed ${ }^{14}$. There was no report for prevalence and factors of silent OSA in patients with dentofacial deformities without obstructive sleep apnea symptoms using polysomnography, althogh prevalence of symptomtmatic OSA on dentofacial deformities and maxillo-mandibular advancement for OSA treatment were much reported.

The aim of this study was to evaluate prevalence and factors related to silent OSA in patients with dentofacial deformities.

\section{Material And Methods}

\section{Paticipants}

Seventy-two patients (24 male, 48 female) with dentofacial deformities who were performed orthognathic surgery at Department of Oral and Maxillofacial Surgery, Kanazawa University Hospital, Kanazawa, Japan from 2016 to 2020 were included in this study. After providing informed consent, participants were 


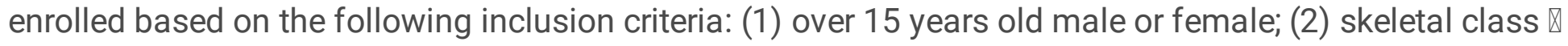
or III dentofacial deformites with or without mandibular asymmetry; (3) without OSA symptoms evaluated by less than 10 of Epworth Sleepiness Scale (ESS) score. Exclusion criteria were as follows: (1) more than two missing posterior teeth, excluding third molars or the use of a removable prosthesis; (2) sleep disorder (e.g. sleep apnea syndrome, narcolepsy); (3) congenital disease including cleft palates; (4) use of medication with possible effects on sleep or motor behavior; (5) alcohol or drug abuse; and (6) major neurological or psychiatric disorders. This study complied with the principles stated in the Declaration of Helsinki Ethical Principles for Medical Research Involving Human Subjects, adopted by the 18th World Medical Assembly. The requirement for IRB has been approved by Kanazawa University Hospital Research Ethical Committee (Ref. No.1765-1).

\section{Silent obstructive sleep apnea evaluation using polysomnography}

We defined silent obstructive sleep apnea (OSA) as present in patients who were undiagnosed at initial surgical consultation but were then confirmed by an attended PSG and evaluation by a pulmonologist to have symptomatic OSA. Prior to orthognathic surgery, interviews with Epworth Sleepiness Scale (ESS) and polysomnography were performed, Polysomnography was performed before orthognathic surgery (Embla N7000 with MDrive, CHEST, Japan) by two sleep technicians during over night evaluation and diagnosed OSA by a pulmonologist. The sleep quality and respiratory status were evaluated by sleeping hours, sleeping efficiency, rapid eye movement (REM) sleep phase, non-rapid eye movement (NREM), apnea-hypopnea index (AHI), oxygen desaturation index (ODI), Lowest peripheral oxygen saturation (lowest SPO2), average SPO2 and cumulative percentage time at SpO2 below $90 \%$ during the measurement (CT90). Sleeping efficiency was calculated (REM sleep time + NREM sleep time) / total sleep time.

\section{Risk factors related to silent obstructive sleep apnea}

ESS, sleep time, sleep efficiency, REM sleep rate, sleep phase (REM/NREM) were evaluated as the sleep factors, age, gender and body mass index (BMI) were evaluated as physical factors, overjet, overbite, SNA angle, SNB angle, ANB angle, SN-MP angle, GZN angle, Go-angle and mandibular deviation using cephalometric analysis were evaluated as the morphological factors.

\section{Statistical analysis}

Statistical relationship between risk factors related to silent OSA in patients with dentofacial deformities and apnea hypopnea index values was analyzed by Linear regression. Comparison between two factors was analyzed by Mann-Whitney test, among 3 or more factors was analyzed by one-way ANOVA test. The level of signicance was set at $p<0.05$. All statistical analysis were performed using GraphPad Prism, version 7 (GraphPad Software, San Diego, CA, USA).

\section{Results}




\section{Prevalence of silent obstructive sleep apnea}

The mean and standard deviation average SPO2 was $97.0 \pm 0.8 \%$ (range: $94.2-98.3 \%$ ). Lowest SPO2 was $92.4 \pm 2.6 \%$ (range: $82.9-96.0$ ). CT90 ( $\mathrm{min}$ ) was $0.014 \pm 0.07$ (range: $0-0.5$ ). ODI was $1.3 \pm 2.7$ (range:0-21.6) and AHI was $1.6 \pm 1.9$ (0-12.1). Three patients (two male and one female) with skeletal class 3 dentofacial deformity of 72 patients (4.1\%) were diagnosed silent OSA (AHI: 12.1, 8.5, 6.4, Age: 31, 25, 54, BMl: 33, 20, 31 ) (Table.1).

\section{Risk factors related to silent obstructive sleep apnea}

REM sleep phase, BMI, Gender, overbite, mandibular deviation were related to prevalence of OSA (Table 2). AHI during REM sleep phase $3.7 \pm 5.2$ (0-32.3) was statistically higher than AHI during NREM sleep phase $1.0 \pm 1.6$ (0-9.7) (Fig. 2). AHI of male patients $2.6 \pm 2.7$ (0-12.1) was higher than that of female $1.0 \pm 1.1$ (0-6.4) (Fig. 3). AHI was increased according to high BMI (Fig. 4). AHI was higher in deep bite $3.2 \pm 3.7(0.2-12.1)$ than open bite $1.1 \pm 1.0(0-3.4)$, edge to edge bite $1.0 \pm 1.2(0-4.4)$ and nomal bite $1.6 \pm 1.5(0.2-6.4)$ (Fig. 5). AHI of mandibular asymmetry cases $2.0 \pm 2.3(0-12.1)$ were higher than that of symmetry cases $1.1 \pm 1.3(0-6.4)$ (Fig. 6).

\section{Discussion}

We defined silent OSA is first observed $5 \leq \mathrm{AHI}$ by polysomnography even if patient ESS under 10 . The Epworth Sleepiness Scale (ESS) is established as self-reporting questionnaire used by the clinical assessment an individual's level of daytime sleepiness ${ }^{15}$. In clinical practice, ESS scores of 11-24 represent increasing levels of 'excessive daytime sleepiness' to recommend for OSA examination. The diagnosis for OSA is defined as follows: normal, $\mathrm{AHI}<5$; mild sleep apnea, $5 \leq \mathrm{AHI}<15$; moderate sleep apnea, $15 \leq \mathrm{AHI}<30$; severe sleep apnea, $\mathrm{AHI} \geq 30^{16}$. In this study, 3 patients of 72 patients (4.1\%) were diagnosed mild silent OSA although they had no symptom of OSA before polysomnography evaluation. Posnick et al reported $23 \%(60$ of 262)had silent OSA with dentofacial deformities exceeded that estimated in the general population by PSG confirmed. This prevalence rate of $23 \%$ was remarkable higher than our results of $4.1 \%$ although these two studies were performed both dentofacial deformities. Prevalence of OSA was reported in the range of 3 to $7 \%$ for adult men and 2 to $5 \%$ for adult women ${ }^{17-20}$ in Asia, however, in the range of $13-33 \%$ in adult men and $6-19 \%$ for adult women, in Europe and North America $^{21}$. LI et al ${ }^{22}$ evaluated the possible differences between Asian and White patients with OSA and reported that the Asian patients were less obese and had maxillomandibular protrusion, narrower cranial base angle, larger posterior airway space, and more superiorly positioned hyoid bone compared with the White patients. Mandibular protrusion has a wider airway than that of normal occlusion without dentofacial deformities ${ }^{9}$. For that reason, silent OSA in our study targeted Japanese was low rate may be due to difference of ethnicity between Asian and White patients. Ethnicity was one of the risk factors of OSA was reported ${ }^{23}$. 
Further in previous research, male gender, obesity, age, and craniomaxillofacial morphology are considered to be predictable factors for development of OSA too ${ }^{23}$. Regarding gender, OSA was more prevalent in male than female regardless of ethnicity ${ }^{17-21}$. These facts supported our result of OSA in male was higher than in female even if participants were Asian in this study. Anatomical differences or sex hormone are cause for OSA differences between male and female was reported. Pharyngeal airway anatomy or tissue characteristics between males and females has fundamental difference and males are more susceptible than females to load-induced hypoventilation because of the increased airway collapse ${ }^{24}$. A low testosterone level results in a higher OSA risk ${ }^{25}$ and Estrogen protects against OSA by exerting antidepressant and sleep effects ${ }^{26}$. A reduced estrogen level could affect the level of serotonin, which controls the tongue and palate muscle tone. In women who are pregnant or with menopause, the OSA risk is higher ${ }^{27}$. Regarding obesity, It was also greater in obese men and women compared with overweight men and women ${ }^{21}$. According to World Health Organization definitions, BMI $\geq 30 \mathrm{~kg} / \mathrm{m} 2$ can be defined as obesity, and BMI $25-29.9 \mathrm{~kg} / \mathrm{m} 2$ can be defined as overweight ${ }^{28}$. Two of three patients with silent OSA of BMI in our study were over $30 \mathrm{~kg} / \mathrm{m} 2$ was convincing results.

. Regarding age, The prevalence of OSA in the elderly population was remarkably high was reported. This was $88 \%$ in men and $66 \%$ in female aged $65-69$ years old ${ }^{29}, 90 \%$ in men and $78 \%$ in female aged $60-85$ years old ${ }^{21}$. The reason is why there is no significant relationships with age in our study may be our participants were almost under 50 years old and young. Regarding morphology, another previous study 30 suggested that skeletal conditions such as short mandibular body and mandibular retrusion, size of the tongue, position of the hyoid bone, and shape of the airway are factors that contribute greatly to a further increase in the severity of OSA syndrome in males. On the other hand, mandibular protrusion has a wider airway than that of normal occlusion without dentofacial deformities ${ }^{9}$. We speculated before study that large ANB angle and small SN-MP angle will be the factors related to prevalence of silent OSA. However, overbite and mandibular asymmetry were related to prevalence of silent OSA. Although mandibular retrusion was included in our study, patients with symptomatic OSA were excluded was may be the reason different factors had in silent OSA. However, large overbite generally indicate short face pattern and asymmetry was reported as factor related to OSA in previous study. Our results was should be considered to risk factors of silent OSA.

Guillminault et $\mathrm{al}^{31}$ and RILEY et al ${ }^{32}$ reported on female patients who developed OSAS after bilateral mandibular osteotomies for treatment of skeletal Class III malocclusion. Two other patients with relatively high values of $3 \% \mathrm{ODI}(26.0$ and 19.9 at T1) were mildly obese (BMls of $26.2 \mathrm{~kg} / \mathrm{m} 2$ and 27.3 $\mathrm{kg} / \mathrm{m} 2)$ and their amounts of mandibular setback were comparatively large $(10.4 \mathrm{~mm} \text { and } 13.0 \mathrm{~mm})^{33}$. A large amount of mandibular setback might inhibit biological adaption and cause sleep-disordered breathing, and it might be better to consider maxillary advance or another technique that does not reduce the airway for patients with skeletal class III malocclusions who have large anteroposterior discrepancy and/or maxillary hypoplasia ${ }^{34}$. A systematic review suggested that although the development of postsurgical OSA has been reported, there is no clear evidence that confirms a direct cause-and-effect 
relationship between mandibular setback surgery and OSA development ${ }^{16}$. On the other hand, maxillomandibular advancement (MMA) is the most effective surgical treatment for OSA, with results that are comparable to the efficacy of therapeutic use of continuous positive airway pressure (CPAP) 35,36. Another results showed a high prevalence of acute sleep disturbance. Patients with acute sleep disruption had low postoperative sleep efficiency and impaired functional ability three months after surgery ${ }^{37}$. In this way, maxillamandibular morphology is related to risk of OSA and orthognathic surgery caused perioperative acute respiratory complication or postoperative OSA and improvement OSA by MMA. Preoperative diagnosis for silent OSA is very important alike symptomatic OSA in treatment for dentofacial deformities.

\section{Conclusions}

We require attention to OSA in dentofacial deformities even if without OSA symptoms in particular with obesity, male, deep bite, mandibular asymmetry and REM sleep phase.

\section{Declarations}

\section{Ethics approval and consent to participate}

The requirement for IRB has been approved by Kanazawa University Hospital Research Ethical Committee (Ref. No.1765-1). All patients are informed research purpose and agree to use their clinical data for this study. Informed consent for participation in the study was obtained from their parent or guardian if participants are children (under 16 years old).

\section{Author contributions}

K. $\mathrm{O}$ and $\mathrm{N}$. I designed most of the experiments and wrote the main manuscript text and prepared all figures and tables. K. M and $\mathrm{H}$. $\mathrm{Y}$ are the primary person responsible for carrying out all experimental procedures. T. M analyzed the data. S. K and K. T are the person who made the final approval of the article.

\section{Conflict of interest}

The authors declare that they have no conflicts of interest.

\section{Role of the funding source}

There was no source of funding for this research.

\section{References}

1. Laratta CR, Ayas NT, Povitz M, Pendharkar SR: Diagnosisand treatment of obstructive sleep apnea in adults. CMAJ ;189(48), 1481-1488, 2017. 
2. Drager LF, Togeiro SM, Polotsky VY, Lorenzi-Filho G: Obstructive sleep apnea: a cardiometabolic risk in obesity and the metabolic syndrome. J Am Coll Cardiol, 62(7):569-76, 2013.

3. Cielo CM, Marcus CL: Obstructive Sleep Apnoea in Children With Craniofacial Syndromes, Paediatr Respir Rev, 16(3):189-96, 2015.

4. Ichinohe T, Kaneko Y: Nitrous Oxide Does Not Aggravate Postoperative Emesis After Orthognathic Surgery in Female and Nonsmoking Patients. J Oral Maxillofac Surg May;65(5):936-9, 2007

5. Tajender S Vasu , Ritu Grewal, Karl Doghramji: Obstructive Sleep Apnea Syndrome and Perioperative Complications: A Systematic Review of the Literature. J Clin Sleep Med, 8(2):199-207, 2012.

6. Vigié du Cayla G, Collet JM, Attali V, Kerbrat JB, Benslama L, Goudot P: Long-term effectiveness and side effects of mandibular advancement devices on dental and skeletal parameters. J Stomatol Oral Maxillofac Surg.120(1):7-10, 2019.

7. Vecchierini MF, Attali V, Collet JM, d'Ortho MP, El Chater P, Kerbrat JB, Leger D, Monaca C, Monteyrol PJ, Morin L, Mullens E, Pigearias B, Meurice JC: A custom-made mandibular repositioning device for obstructive sleep apnoea-hypopnoea syndrome: the ORCADES study. Sleep Med. 19:131-40, 2016.

8. Rojo-Sanchis C, Almerich-Silla JM, Paredes-Gallardo V, Montiel-Company JM, Bellot-Arcís C: Impact of Bimaxillary Advancement Surgery on the Upper Airway and on Obstructive Sleep Apnea Syndrome: a Meta-Analysis. Sci Rep.10;8(1):5756, 2018.

9. Takai S, Tanaka R, Kobayashi T, Oda Y, Hayashi T, Saito C: Three-Dimensional CT Evaluation of Upper Airway Morphology in Patients with Jaw Deformity. The Japanese Journal of Jaw Deformities 21.215-224,2011.

10. Riley RW, Powell NB, Guilleminault C, Ware W: Obstructive sleep apnea syndrome following surgery for mandibular prognathism. J Oral Maxillofac Surg 45(5):450-452, 1987

11. Arisaka T, Tonogi M, Tsukamoto $Y$, et al.: Examination of Change Sleep-Disordered Breathing before and after Orthognathic Surgery-Part 2 Change of the Pharyngeal Airway Space. Japanese J Jaw Deform 17(1):16-21, 2007

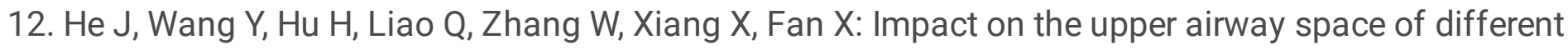
types of orthognathic surgery for the correction of skeletal class $\otimes$ malocclusion: A systematic review and meta-analysis. Int J Surg, 38:31-40, 2017.

13. Gonçales ES, Rocha JF, Gonçales AG, Yaedú RY, Sant'Ana E: Computerized Cephalometric Study of the Pharyngeal Airway Space in Patients Submitted to Orthognathic Surgery. J Maxillofac Oral Surg,13(3):253-8,2014.

14. Chun-Shin Chang, Christopher Glenn Wallace, Yen-Chang Hsiao, Yuh-Jia Hsieh,Yi-Chin Wang, NingHung Chen, Yu-Fang Liao, Eric Jen-Wein Liou, Philip Kuo-Ting Chen, Jyh-Ping Chen, Yu-Ray Chen: Airway Changes After Cleft Orthognathic Surgery Evaluate by Three-Dimensional Computed Tomography and Overnight Polysomnographic Study. Sci Rep 25;7(1):12260, 2017.

15. Senaratna CV, Perret JL, Lodge CJ, Lowe AJ, Campbell BE, Matheson MC, Hamilton GS, Dharmage SC. Prevalence of obstructive sleep apnea in the general population: A systematic review. Sleep Med Rev. 2017 Aug;34:70-81. 
16. Tan SK, Leung WK, Tang ATH, Zwahlen RA (2017) How does mandibular advancement with or without maxillary procedures affect pharyngeal airways? An overview of systematic reviews. PLoS One 12:e0181146

17. Ip MS, Lam B, Lauder IJ, et al: A community study of sleep disordered breathing in middle-aged Chinese men in Hong Kong. Chest 119:62, 2001

18. Ip MS, Lam B, Tang LC, et al: A community study of sleepdisordered breathing in middle-aged Chinese women in Hong Kong: Prevalence and gender differences. Chest 125: 127, 2004

19. Kim J, In K, Kim J, et al: Prevalence of sleep-disordered breathing in middle-aged Korean men and women. Am J Respir Crit Care Med 170:1108, 2004

20. Udwadia ZF, Doshi AV, Lonkar SG, Singh Cl: Prevalence of sleepdisordered breathing and sleep apnea in middle-aged urban Indian men. Am J Respir Crit Care Med 169:168, 2004

21. Heinzer R, Vat S, Marques-Vidal P, Marti-Soler H, Andries D, Tobback N, et al. Prevalence of sleepdisordered breathing in the general population: the HypnoLaus study. Lancet Respir Med 2015;3(4):310e8.

22. Li KK, Powell NB. A comparison of Asian and white patients with obstructive sleep apnea syndrome. Laryngoscope 1999: 109: 1937-1940.

23. Li KK, Riley RW, Powell NB, Troell R, Guilleminault C. Overview of phase II surgery for obstructive sleep apnea syndrome. Ear Nose Throat J 1999;78:851,854-7.

24. Pillar G, Malhotra A, Fogel R, Beauregard J, Schnall R, White DP, Airway mechanics and ventilation in response to resistive loading during sleep: influence of gender. Am J Respir Crit Care Med 162:16271632,2000

25. Burschtin O, Wang J (2016) Testosterone deficiency and sleep apnea. Urol Clin North Am 43:233237

26. Lozo T, Komnenov D, Badr MS, Mateika JH (2017) Sex differences in sleep disordered breathing in adults. Respir Physiol Neurobiol 245:65-75

27. Behan M, Wenninger JM (2008) Sex steroidal hormones and respiratory control. Respir Physiol Neurobiol 164:213-221

28. World Health Organization. Obesity and overweight. Fact sheet no 311 January (2016; Available from)) http://www.who.int/mediacentre/ factsheets/fs311/en/

29. Lee SD, Kang SH, Ju G, Han JW, Kim TH, Lee CS, et al. The prevalence of and risk factors for sleepdisordered breathing in an elderly Korean population. Respiration 2014;87(5):372e8.

30. Ishiguro K, Kitamura N, Kobayashi T, Saito S. Relationship between severity of sleep-disordered breathing and craniofacial morphology in Japanese male patients. Oral Surg Oral Med Oral Pathol Oral Radiol Endod 2009: 107: 343-349.

31. GUILLEMINAULT C, RILEY R, POWELL N:Sleep apnea in normal subjects following mandibular osteotomy with retrusion.Chest 1985: 88: 776-8. 
32. RILEY R, POWELL N, GUILEMINAULT C,WARE W. Obstructive sleep apnea syndrome following surgery for mandibular prognathism. J Oral Maxillofac Surg1987: 45: 450-2.

33. K. Kitagawara, T. Kobayashi, H. Goto, T. Yokobayashi, N. Kitamura, C. Saito: Effects of mandibular setback surgery on oropharyngeal airway and arterial oxygen saturation, Int. J. Oral Maxillofac. Surg. 2008; 37: 328-333

34. D. Hasebe, T. Kobayashi, M. Hasegawa, T. Iwamoto, K. Kato, N. Izumi, Y. Takata, Saito: Changes in oropharyngeal airway and respiratory function during sleep after orthognathic surgery in patients with mandibular prognathism.

35. Gregoire C, Goodday R, Robertson C: The effect of maxillomandibular advancement surgery on controlled positive airway pressure (CPAP) use in patients with obstructive sleep apnea syndrome. J Oral Maxillofac Surg 63(Suppl 1):48,2005.

36. Holty J, Guilleminault C: Maxillomandibular advancement for the treatment of obstructive sleep apnea: A systematic review and meta-analysis. Sleep Med Rev 14:287, 2010.

37. Mitsuru Ida, Hiroki Onodera, Motoo Yamauchi, Masahiko Kawaguchi: Preoperative sleep disruption and postoperative functional disability in lung surgery patients: a prospective observational study, Journal of Anesthesia, 33:501-508, 2019.

\section{Tables}

Due to technical limitations, table 1, 2 is only available as a download in the Supplemental Files section.

\section{Figures}




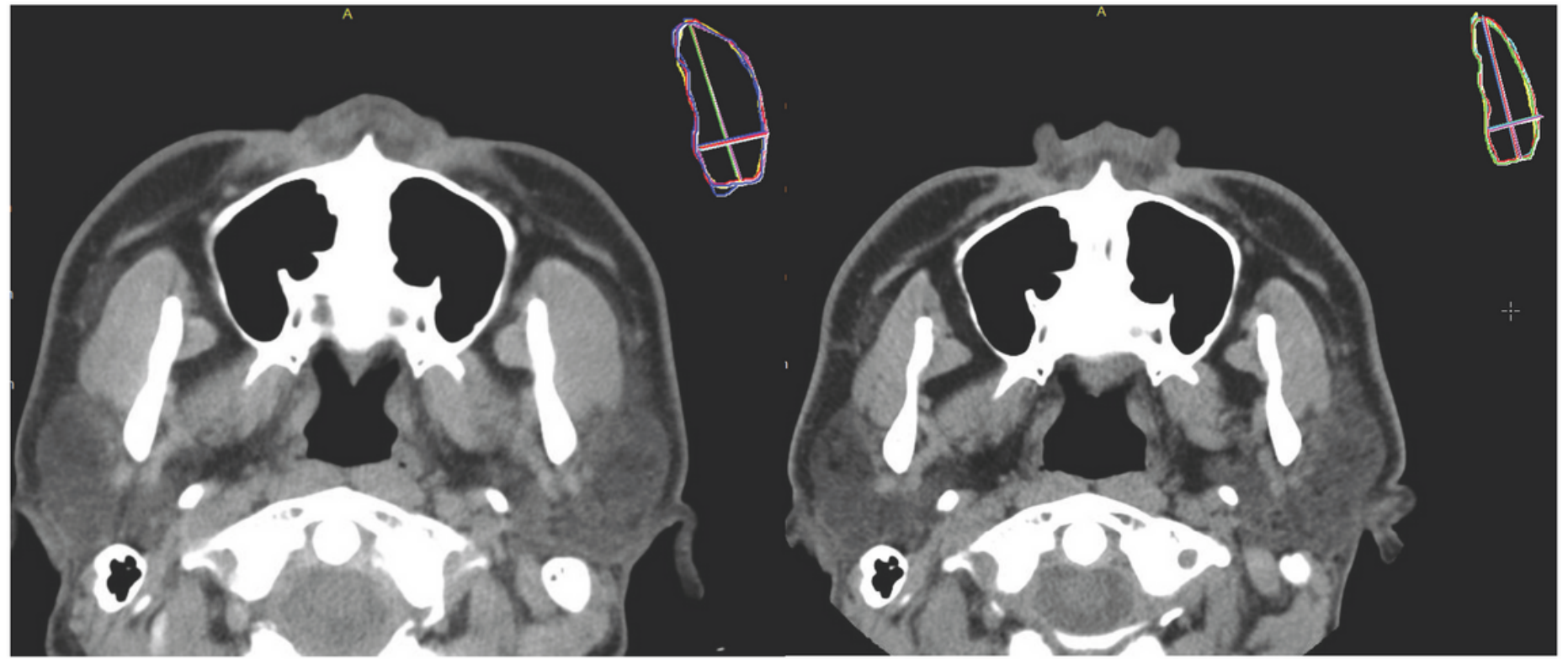

before POOT

\section{after POOT}

POOT: preoperative orthodontic treatment

Figure 1

Measurements of cross sectional masseter muscle using CT images
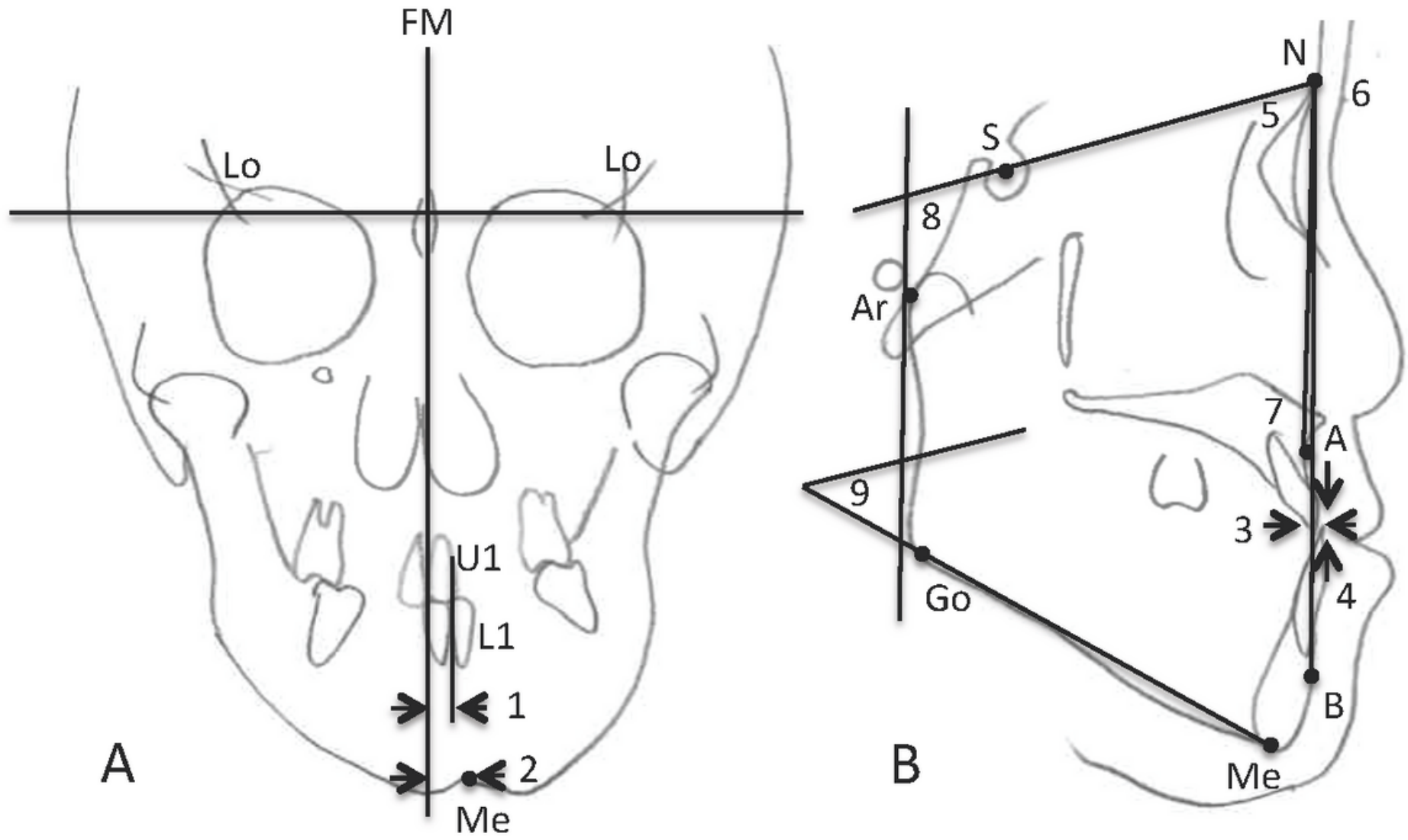
Figure 2

Cephalometric measurements A: Anteroposterior cephalometric measurements. 1;DFFM at Menton (mm), 2;U1-L1 deviation $(\mathrm{mm})$ B: Lateral cephalometric measurements 3;overjet $(\mathrm{mm})$, 4;overbite $(\mathrm{mm})$, S;SNA

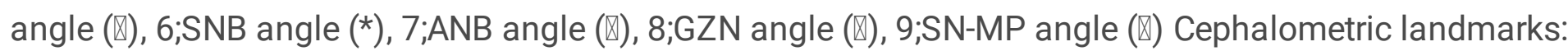
menton (Me), midpoint of the upper incisor edge (U1), midpoint of the lower incisor edge (L1), sella (S), nasion $(N)$, point $A(A)$, point $B(B)$, gonion (Go), articulare (Ar) FM: facial midline, DFFM :Deviation from the facial midline

length

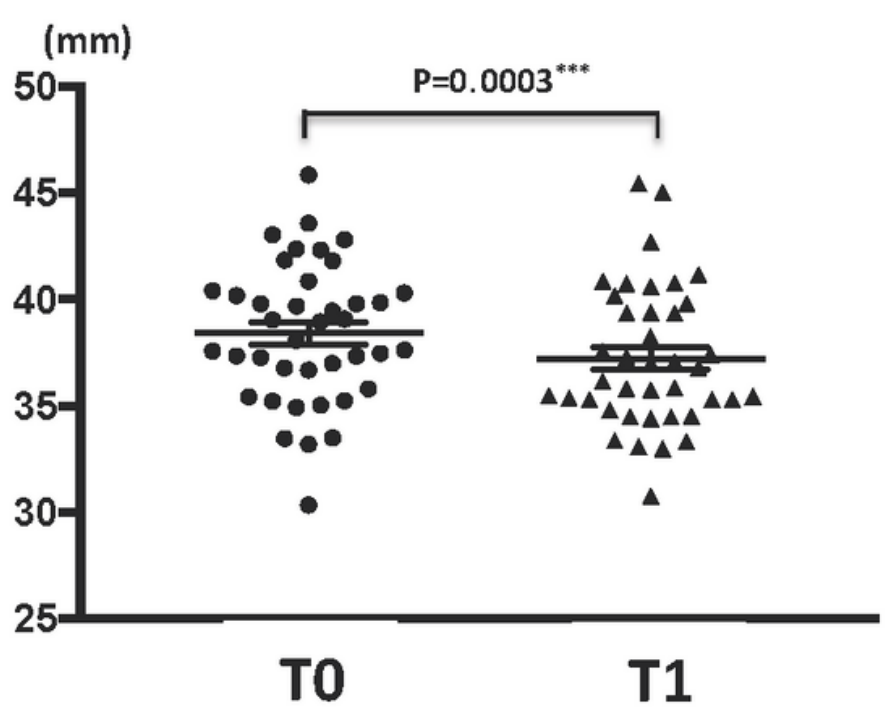

\section{width}

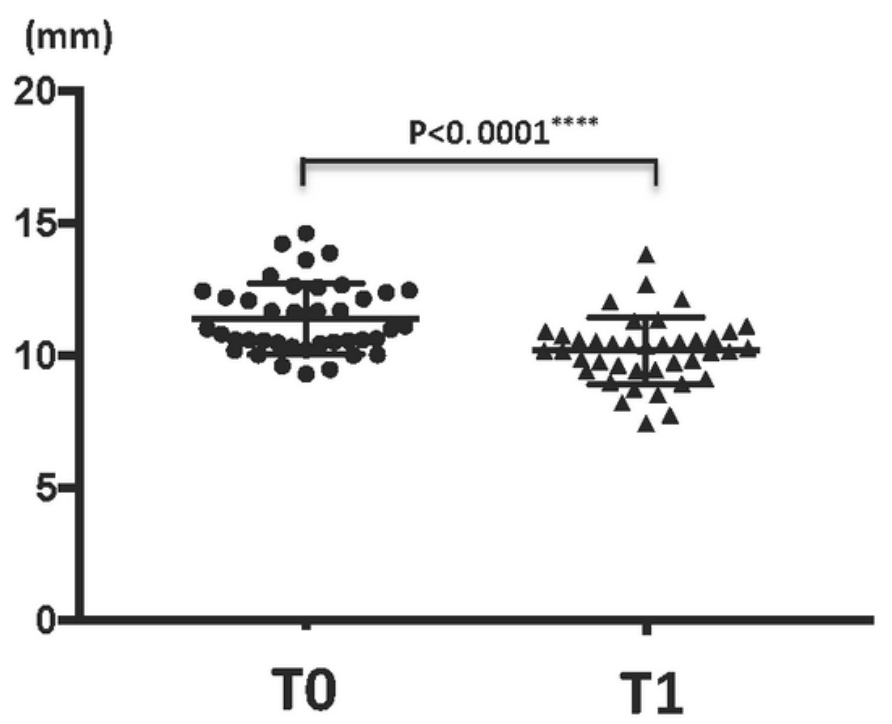

\section{cross sectional area}

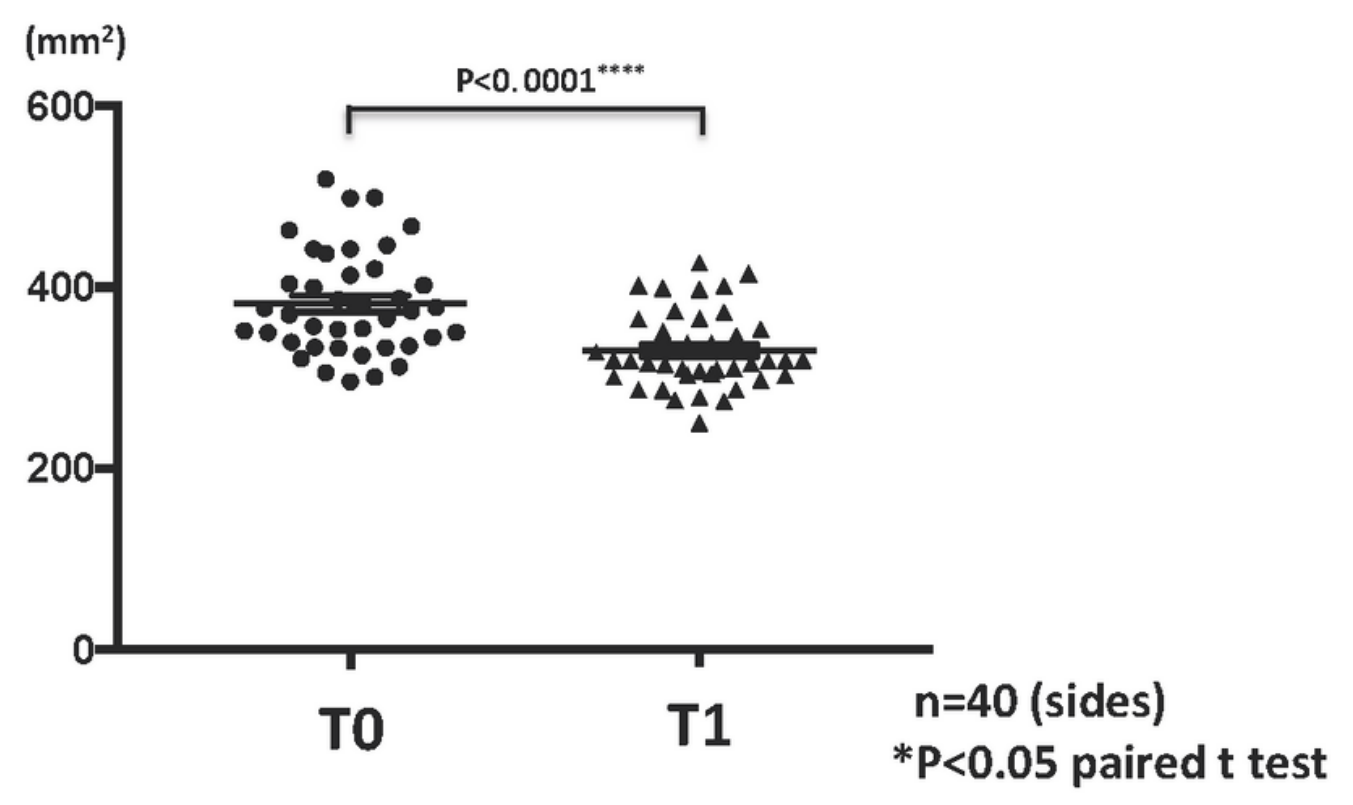

T0: pretreatment

T1: after preoperative orthodontic treatment 
Figure 3

Comparison of masseter muscle length, width and area between before and after preoperative orthodonthic treatment

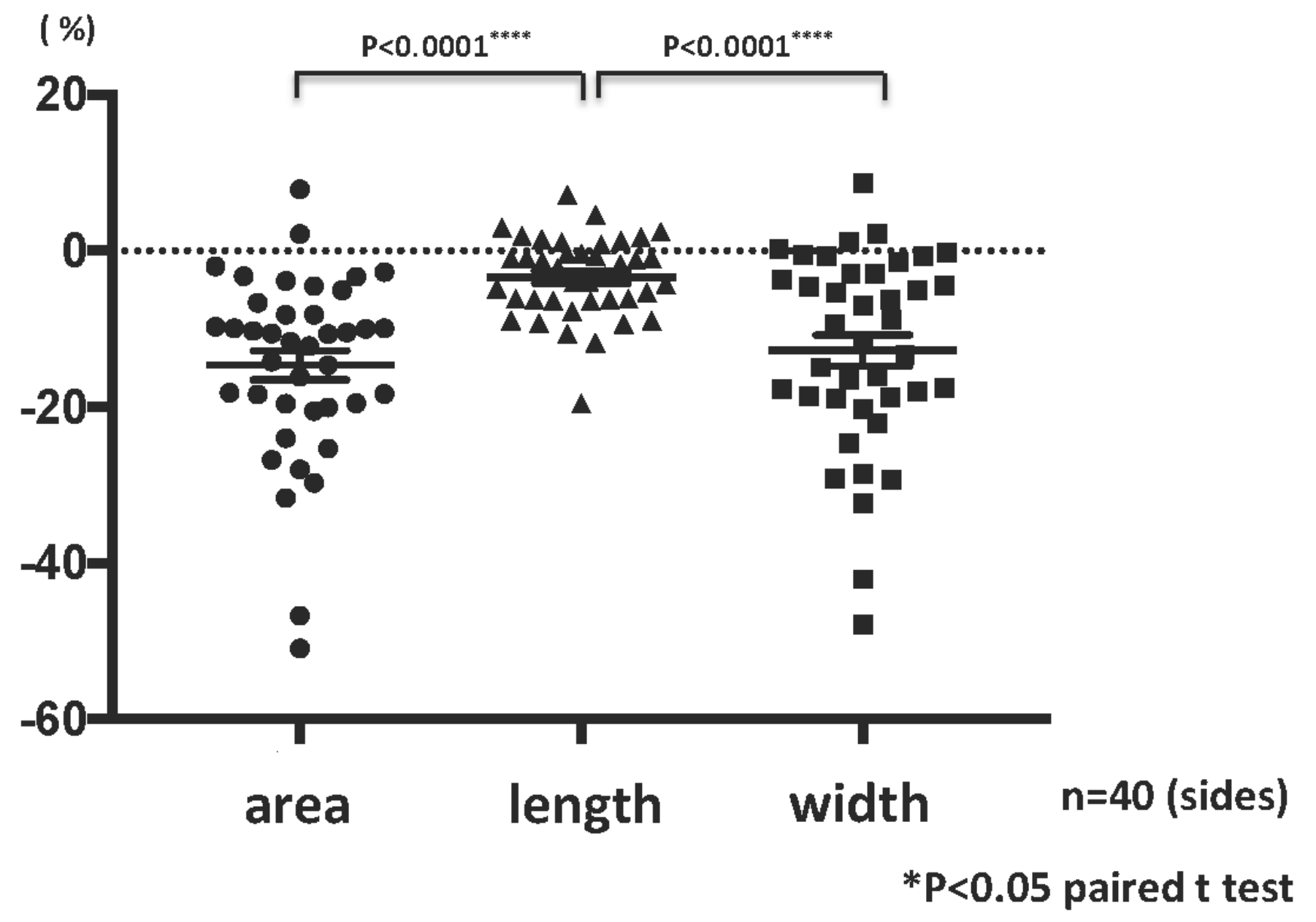

Figure 4

Change rate of masseter muscle length, width and area after preoperative orthodontic treatment 


\section{Change of overbite}

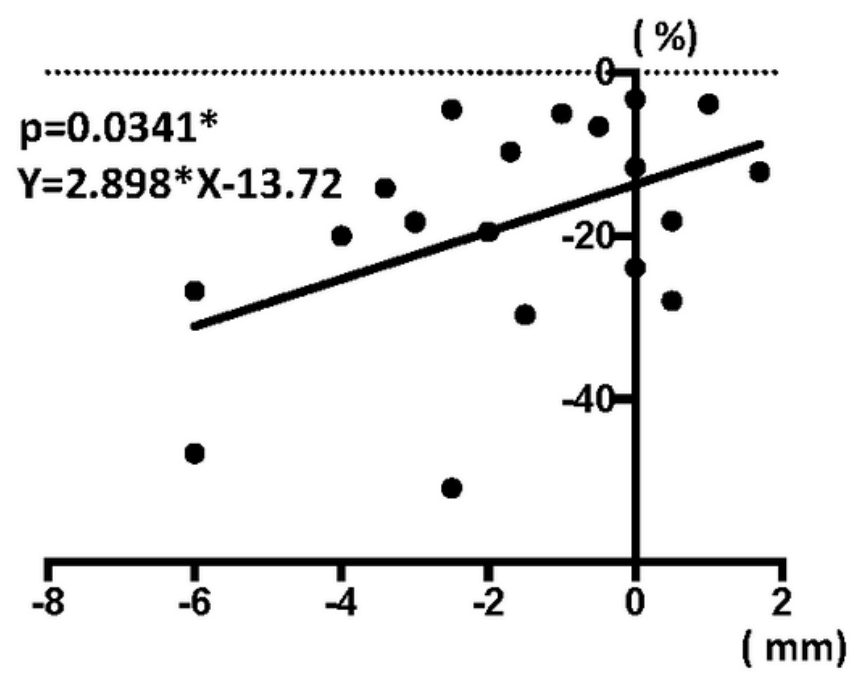

SNA angle

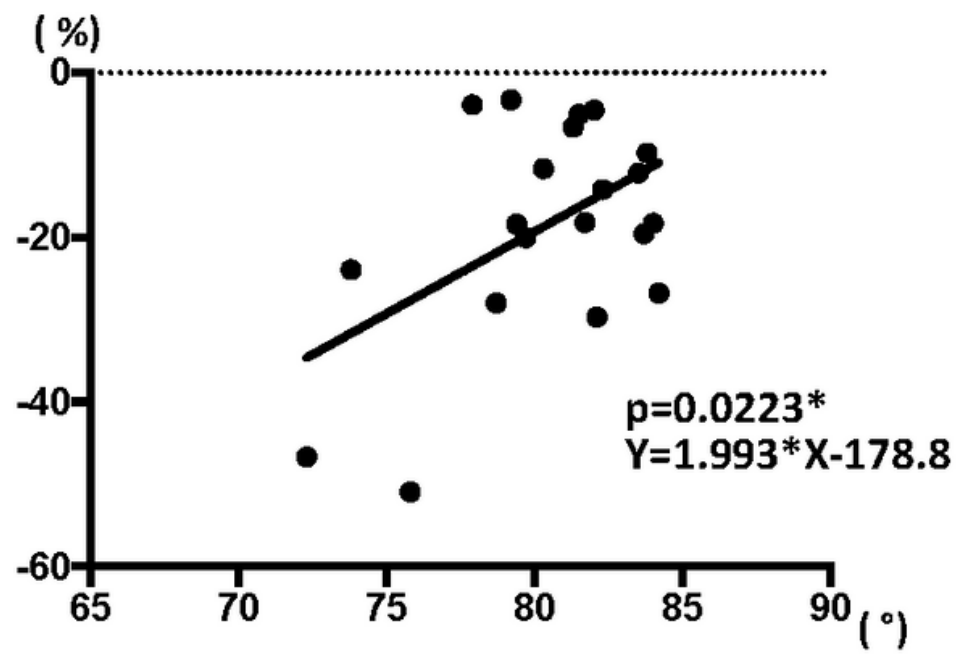

${ }^{*} p<0.05$ Linear regression

Figure 5

Relations between changes of cross sectional masseter muscle area and changes of overbite and SNA angle

\section{Supplementary Files}

This is a list of supplementary files associated with this preprint. Click to download.

- 2020JokajipaperTable.pdf 